on the discrimination between AS patients and controls (AUC 0.827 in young males).

Table 1. Demographic and clinical characteristics

\begin{tabular}{lccc}
\hline & $\mathrm{nr}$-axSpA & AS & control \\
\hline & $\mathrm{n}=150$ & $\mathrm{n}=58$ & $\mathrm{n}=14$ \\
\hline Age, $\mathrm{y}$ (mean, SD) & $31(6.9)$ & $32(7.4)$ & $30(7.0)$ \\
Male, $\mathrm{n}(\%)$ & $68(45.3)$ & $26(44.8)$ & $4(28.5)$ \\
Symptom duration, m (median, IQR) & $35(13-98)$ & $111(27-176)$ & - \\
HLA B27 positive, $\mathrm{n}(\%)$ & $103(68.7)$ & $48(82.8)$ & - \\
Peripheral manifestations, $\mathrm{n}(\%)$ & $41(27.3)$ & $18(31.0)$ & - \\
Extra-articular manifestations, $\mathrm{n}(\%)$ & $32(21.3)$ & $19(32.8)$ & - \\
BASDAI (mean, SD) & $4.4(1.97)$ & $4.1(2.03)$ & - \\
CRP $>$ ULN, $\mathrm{n}(\%)$ & $45(30.0)$ & $33(56.9)$ & - \\
\end{tabular}

Table 2. Performance of anti-CD74 IgA in discriminating nr-axSpA from controls, according to sex and age (young: $<32$ y/o). $A U C=$ area under the curve, PPV/NPV = positive/negative predictive value, $\mathrm{LR}+=$ positive likelihood ratio.

Cut-off (U/mL) AUC Sensitivity (\%) Specificity (\%) PPV (\%) NPV (\%) LR+

\begin{tabular}{llllllll}
\hline Male \& young & 16.9 & 0.806 & 65.8 & 92.3 & 96.2 & 48.0 & 8.6 \\
Male \& old & 17.4 & 0.795 & 55.6 & 92.3 & 93.8 & 50.0 & 7.2 \\
Female \& young & 16.7 & 0.647 & 50.0 & 92.3 & 94.4 & 41.4 & 6.5 \\
Female \& old & 16.9 & 0.741 & 46.8 & 92.3 & 95.7 & 42.2 & 6.0
\end{tabular}

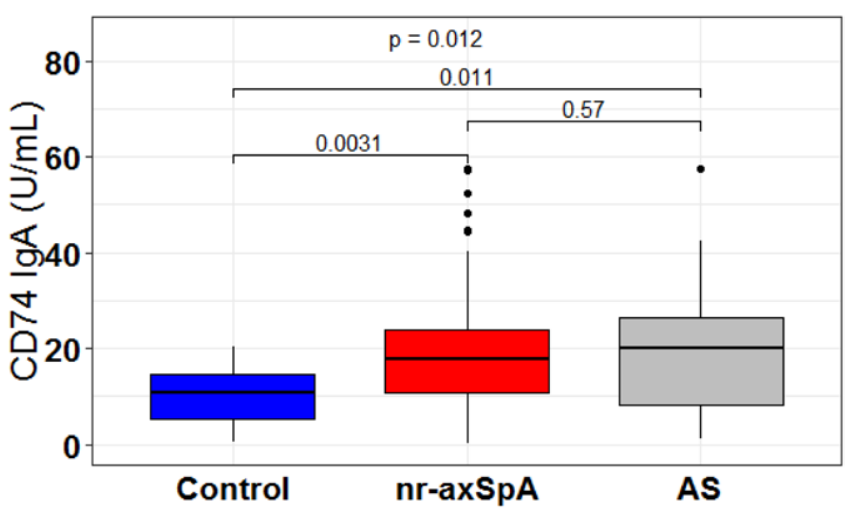

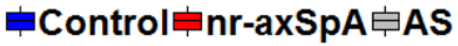

Figure 1. Univariate comparison of anti-CD74 IgA concentrations between $\mathrm{nr}-\mathrm{axSpA}, \mathrm{AS}$ and control patients $(<45 \mathrm{y} / 0)$.

Conclusion: In this study, mean anti-CD74 IgA concentrations were higher in axial SpA patients compared to non-SpA controls. Application of this biomarker in young $(<32$ y/o) male nr-axSpA or AS patients yielded the highest sensitivity and specificity.

References:

[1] Riechers E, Baerlecken N, Baraliakos X, et al. Sensitivity and Specificity of Autoantibodies Against CD74 in Nonradiographic Axial Spondyloarthritis. Arthritis Rheumatol. 2019;71(5):729-35.

Acknowledgments: Aesku.Diagnostics (Wendelsheim, Germany) provided the ELISA kits.

Disclosure of Interests: Ann-Sophie De Craemer: None declared, Torsten Witte: None declared, Liselotte Deroo: None declared, Thomas Renson: None declared, Philippe Carron: None declared, Filip van den Bosch Consultant of: AbbVie, Celgene Corporation, Eli Lilly, Galapagos, Janssen, Novartis, Pfizer, and UCB, Speakers bureau: AbbVie, Celgene Corporation, Eli Lilly, Galapagos, Janssen, Novartis, Pfizer, and UCB, Xenofon Baraliakos Grant/research support from: Grant/research support from: AbbVie, BMS, Celgene, Chugai, Merck, Novartis, Pfizer, UCB and Werfen, Consultant of: AbbVie, BMS, Celgene, Chugai, Merck, Novartis, Pfizer, UCB and Werfen, Speakers bureau: AbbVie, BMS, Celgene, Chugai, Merck, Novartis, Pfizer, UCB and Werfen, Dirk Elewaut: None declared

DOI: 10.1136/annrheumdis-2020-eular.4099

\section{FRI0313 \\ DOES INTERSTITIAL LUNG DISEASE REPRESENT A REAL COMORBIDITY IN SPONDYLOARTHRITIS PATIENTS? RESULTS FROM AN ULTRASOUND MONOCENTRIC PILOT STUDY}

A. Delle Sedie ${ }^{1}$, E. Calabresi ${ }^{2}$, I. Romagnoli ${ }^{1}$, L. Carli ${ }^{1}$, M. Mosca ${ }^{1} .{ }^{1}$ University of Pisa, Rheumatology Unit, Pisa, Italy; ${ }^{2}$ Medical University of Pisa, Pisa, Italy

Background: Interstitial lung disease (ILD) is a frequent complication in rheumatoid arthritis (RA) where it represents the most common extra-articular involvement (with a prevalence of about 10-60\%) and the second cause of mortality (after cardiovascular diseases). Spondyloarthritides (SpA) are chronic arthritides that share with RA both a similar disease burden and similar therapeutical approaches. ILD evaluation is challenging, given the low sensitivity of X-ray and pulmonary function tests, and radiation linked to repetitive HRCT. Lung Ultrasound (LUS) has shown potential in the evaluation of ILD in autoimmune diseases.

Objectives: To assess the prevalence of ILD in a cohort of SpA patients (pts) using LUS with respect to healthy controls $(\mathrm{HC})$.

Methods: Consecutive SpA out-pts were examined by LUS, applying the definition for pleural line irregularity $(\mathrm{PLI})$ recently provided by the OMERACT taskforce for LUS in systemic sclerosis (1). Seventy-one intercostal spaces were studied (14 in the anterior chest, 27 lateral and 30 posterior) in all the pts/HC using an Esaote MyLab25 Gold US machine with a linear 7.5-10 MHz probe. The scoring system by Pinal-Fernandez et al (2) was applied and a total pleural score was calculated. Each patient answered to Italian-validated PROs on respiratory function (Leicester and Saint-George), global health (SF-36) and dyspnea (mMRC scale). Clinical data on disease-duration, disease-onset, disease-activity (at the moment of the examination) and MTX/biologics treatment were collected from the medical records.

Results: Fifty-six SpA pts (35 psoriatic arthritis -PsA- and 21 ankylosing spondylitis -AS-) and $56 \mathrm{HC}$ were studied. No significant differences were demonstrated between groups ( $\mathrm{SpA}$ vs $\mathrm{HC}$ and PsA vs AS) for age, sex, BMI and smoking habits. The total pleural score was significantly higher in SpA pts than in $\mathrm{HC}(20.9 \pm 11.8$ vs $10.3 \pm 7.7 ; \mathrm{p}<0.001)$. A positive correlation was found between total PLI score and PLI score from anterior, posterior and lateral chest. The posterior part of the chest showed a higher PLI score than the anterior and lateral one (with the latter resulting to be significantly lower than the posterior PLI score). Higher differences in the PLI average value between SpA pts and $\mathrm{HC}$ were registered for posterior and anterior part of the chest. No differences were found between PsA and AS (with a not statistically significant difference in the posterior PLI score, which was slightly higher in AS pts) (Tab.I).

Table 1. average $\mathrm{PLI}$ score $(\mathrm{N} \pm \mathrm{SD})$

\begin{tabular}{llrrr}
\hline & \multicolumn{1}{c}{ Total } & Anterior & Posterior & Lateral \\
\hline HC & $10.3 \pm 7.7$ & $4 \pm 3.2$ & $5 \pm 3.7$ & $1.4 \pm 2.2$ \\
PsA & $20.1 \pm 12.5$ & $6.8 \pm 3.9$ & $10.2 \pm 6.9$ & $2.9 \pm 4.1$ \\
AS & $22.1 \pm 10.7$ & $7 \pm 2.8$ & $12 \pm 9.5$ & $3 \pm 3.1$ \\
\hline
\end{tabular}

Conclusion: LUS examination shows a higher amount of PLI in SpA with respect to $\mathrm{HC}$.

References:

[1] Delle Sedie A et al. Ann Rheum Dis 2019;78(Suppl 2):A834

[2] Pinal-Fernandez I et al. Clin Exp Rheumatol 2015;33(4 Suppl 91):S136-41 Disclosure of Interests: Andrea Delle Sedie Speakers bureau: MSD, Lilly, Novartis, Abbvie, Celgene, Emanuele Calabresi: None declared, Ilaria Romagnoli: None declared, Linda Carli: None declared, Marta Mosca: None declared

DOI: 10.1136/annrheumdis-2020-eular.4616

\section{FRI0314}

ANNUAL DIAGNOSTIC PREVALENCE OF ANKYLOSING SPONDYLITIS (AS) IN THE UNITED STATES USING MEDICARE AND MARKETSCAN DATA

J. Curtis ${ }^{1}$, K. Winthrop ${ }^{2}$, B. Chan ${ }^{2}$, S. Siegel ${ }^{2}$, J. Stark $^{3}$, R. Suruki ${ }^{4}$, R. Bohn ${ }^{4}$, F. Xie ${ }^{1}$, H. Yun ${ }^{1}$, L. Chen ${ }^{1}$, A. Deodhar ${ }^{2}$. 'University of Alabama at Birmingham, Birmingham, United States of America; ${ }^{2}$ Oregon Health \& Science University, Portland, United States of America; ${ }^{3}$ UCB Pharma, Smyrna, United States of America; ${ }^{4}$ UCB Pharma, Raleigh, United States of America

Background: Axial spondyloarthritis (axSpA) is a chronic inflammatory disease that affects the axial skeleton and sacroiliac joints, and can be classified as ankylosing spondylitis (AS) or non-radiographic (nr)-axSpA. ${ }^{1}$ A 2016 analysis estimated the US diagnostic prevalence of axSpA to be $0.2 \%$ and $A S$ to be $0.1 \%{ }^{2}$ Previous studies use disparate populations and diagnostic definitions; ${ }^{3,4}$ it is therefore unclear how AS prevalence has changed over time. 